\title{
Buzağılarda Doğum Sırasında ve Sonrasında Şekillenen Kırık Olgularının ve Sağaltım Yöntemlerinin Değerlendirilmesi
}

\author{
İbrahim YURDAKUL* \\ Sivas Cumhuriyet Üniversitesi, Veteriner Fakültesi, Cerrahi Anabilim Dalı, Sivas, Türkiye.
}

Gelis Tarihi: 11.07.2018

Kabul Tarihi: 03.12.2018

Özet: Bu çalışmada; 2016-2018 yılları arasında kliniklerimize kırık şikayeti ile getirilmiş farklı yaş, ırk ve cinsiyetteki buzağıların doğum sırasında veya sonrasında şekillenen kırık olguları ile bu kırıkların sağaltım yöntemlerinin değerlendirilmesi amaçlandı. Toplam 28 buzağıda kırık tespit edildi. Cinsiyete göre kırık olgularının erkeklerde (\%64.29); dişilere (\%35.71) oranla daha fazla görüldüğü belirlendi. Irklara göre kırık olgularına en fazla Simental (\%53.57) ırk buzağılarda rastlandı. Buzağılarda tespit edilen olguların 16'sının (\%57.14) doğum sırasında, 12'sinin (\%42.86) ise doğum sonrası düşme, vurma gibi travmalara bağlı oluştuğu belirlendi. Kırık olguları içerisinde en çok metakarpus kırıklarına (\%32.14) rastlandı; bunu metatarsus (\%17.86), tibia (\%17.86), femur (\%10.71), mandibula (\%10.71), humerus (\%7.14) ve scapula (\%3.57) kırıkları izledi. Sağaltım amacıyla konservatif olarak toplam 10 olguya polivinil klorür (PVC) destekli alçılı bandaj, 5 olguya PVC destekli bandaj, operatif olarak 6 olguya intramedüller pin, 3 olguya intramedüller pin ve serklaj uygulaması, 3 olguya akrilik eksternal fiksasyon ve 1 olguya ise sadece serklaj teli kullanılarak fiksasyon uygulandı. Sonuç olarak, hayvan sahiplerinin güç doğum olgularına müdahale etmemeleri, buzağıların doğumdan sonra travmalara maruz kalmamaları için belli bir döneme kadar gereken koruyucu önlemleri almaları, buzağılarda şekillenen kırık olgularına ampirik yöntemlerle müdahale etmemeleri ve en kısa sürede bir veteriner hekime başvurmaları konusunda bilinçlendirilmeleri gerektiği kanısına varıldı.

Anahtar Kelimeler: Buzağı, Güç doğum, Kırık, Sağaltım yöntemleri.

\section{Treatment Methods and Evaluation of Fracture Cases Shaped During and After Birth in Calves}

Abstract: The aim of this study was to evaluate the fracture cases which occured peri- or postpartum period on calves with different race, gender and age, presented to the Animal Hospital of Cumhuriyet University Veterinary Faculty between 2016-2018 as well as treatment methods of these cases In the study 28 calves with extremity fractures were detected. According to the sex, it was determined that the incidence of fractures were higher in males (64.29\%); than females (35.71\%). According to the races, fracture cases were mostly encountered in Simmental (53.57\%). It was determined that $16(57.14 \%)$ of the cases were found to be traumatized during birth and $12(42.86 \%)$ were found to be postpartum. the Most common cases were metacarpus fractures (32.14\%); followed by fractures of metatarsus (17.86\%), tibia (17.86\%), femur $(10.71 \%)$, mandible (10.71\%), humerus $(7.14 \%)$ and scapula (3.57\%). As a conservative method, a total of 10 cases were treated with PVC supported plaster bandage, 5 cases with PVC supported bandage, 6 patients were treated operatively with intramedullary pin, 3 patients with intramedullary pin and cerclage, 3 cases acrylic external fixation and 1 case cerclage wire. As a result, it was concluded that animal owners should not intervene in the cases of dystocia, take precautions for a certain age to prevent the trauma of the animals after birth, empirically intervene in the fractures formed in the calves and be aware of the nearest veterinary applications.

Keywords: Calf, Dystocia, Fracture, Treatment.

\section{Giriş}

Buzağılarda uzun ekstremite kırıkları sıklıkla şekillenmektedir (Arıcan ve ark., 2014). En fazla metakarpus ve metatarsus, femur, tibia, radius ve ulna, vertebra ve humerus kırıklarıyla karşılaşılır. Pelvis, kosta, mandibula ve phalanxlarda oluşan kırıklar nadir olarak görülmektedir (Arıcan ve ark., 2014; El-Shafaey ve ark., 2014; Görgül ve ark., 2004; St-Jean ve ark., 1992). Kırıklara neden olan sebeplerin başında özellikle pelvik kanalın dar olması neticesinde güç doğuma yardım amacıyla yapılan bilinçsiz uygulamalar, hayvanın ayakta doğum yapması esnasında yavrunun zemine veya zemindeki kanala uygunsuz düşmesi, buzağının yatış pozisyonunda iken anne tarafından bacağına basılması, başka bir hayvan tarafından tekmelenmesi ve trafik kazası şeklinde sayılabilir (Belge ve ark., 2016; Ferguson ve ark., 1990; Nuss ve ark., 2011; Tulleners, 1986).

Buzağılarda oluşan kırıkların sağaltımı veteriner ortopedide önemli bir yer tutmaktadır (Durmuş ve ark., 2009). Çiftlik hayvanlarında kırık olgularının tedavisinde hayvanın genetik ve ekonomik değeri, hayvanın ağırlığı, kırık tipi, kırığın lokalizasyonu ve veteriner hekimin deneyimi oldukça önemlidir (ElShafaey ve ark., 2014). Genellikle, bandaj uygulamaları şekillenen kırık olgularında konservatif 
tedavi seçeneğini oluşturmaktadır. Bandaj uygulamaları özellikle diyafizer bölgeyi içeren kapalı ve basit metakarpus ve metatarsus kırıklarında uygulanmaktadır. Ayrıca metakarpus ve metatarsus kırıklarında eksternal fiksasyon yöntemleri de tercih edilmektedir. Kırık fragmentlerinin disloke olduğu, parçalı ve komplike kırıklarda internal fiksasyon yöntemleri (intramedullar pin, serklaj, vida, plak, interlocking pin vb.) kullanılmaktadır (Arıcan ve ark., 2014; Durmuş ve ark., 2009; El-Shafaey ve ark., 2014; Gangl ve ark., 2006; Salcı ve ark., 2016)

Bu çalışmada kliniğimize getirilen buzağılarda belirlenen kırık olgularının ve uygulanan farklı tedavi yöntemlerinin değerlendirilmesi amaçlandı.

\section{Materyal ve Metot}

Çalışma materyalini 2016-2018 yılları arasında Cumhuriyet Üniversitesi Veteriner Fakültesi Hayvan Hastanesi Cerrahi ABD Kliniği'ne kırık şikayeti ile getirilmiş farklı yaş, ırk ve cinsiyetteki toplam 28 buzağı oluşturdu. Hasta sahiplerinden anamnez alınarak buzağı hakkındaki diğer bilgiler ile beraber kayıt altına alındı.

Hastalara rutin klinik ve radyolojik muayeneler yapıldı. Hasta sahibinin onayı alınarak elde edilen klinik ve radyolojik muayene bulgularına göre konservatif sağaltım olarak polivinil klorür (PVC) destekli veya alçılı bandaj, kafes istirahati; operatif olarak ise anestezisi, 0.5-1 ml dozunda Xylazine hydrochloride'in (Rompun, Bayer, $23.32 \mathrm{mg} / \mathrm{ml}$ ) intramusküler enjeksiyonundan sonra lokal olarak lidokain $\mathrm{HCl}$ (Adokain, Sanovel, $20 \mathrm{mg} / \mathrm{ml}$ ) enjeksiyonu ile sağlanan olgularda intramedüller pin, serklaj teli ve eksternal fiksasyon gibi farklı tedavi yöntemleri uygulandı.

\section{Bulgular}

Kırık olguları, yaş, ırk, cinsiyet, kırık saptanan bölge, kırık şekli ve kırık sebebine göre Tablo 1'de gösterilmiştir. Tablo 1'e göre araştırma kapsamında incelenen kırık olgularının yaş aralığı 1-30 gün arasında değişim gösterdiği, cinsiyete göre ise 18 buzağının erkek, 10 buzağının dişi olduğu tespit edildi. Çalışmada 28 buzağıda kırık tespit edildi. Cinsiyete göre kırık olgularının dişilere ( $n=10$, \%35.71) oranla erkeklerde ( $n=18, \% 64.29)$ daha fazla şekillendiği belirlendi. Irklara göre kırık olgularına en fazla Simental ( $n=15, \% 53.57)$ ırkında rastlandı; bunu Montofon ( $n=7, \% 25)$, melez $(n=5$, $\% 17.86)$ ve Jersey $(n=1, \% 3.57)$ ırkları izledi.

Tablo 1. Kırık olgularının yaş, ırk, cinsiyet, kırık şekillenen kemik, kırık çizgisi, kırığın dış ortamla ilişkisi ve kırık sebebine göre dağııımı.

\begin{tabular}{|c|c|c|c|c|c|c|c|c|}
\hline No & $\begin{array}{c}\text { Protokol } \\
\text { no }\end{array}$ & Irk & Cinsiyet & $\begin{array}{l}\text { Yaş } \\
\text { (gün) }\end{array}$ & $\begin{array}{l}\text { Sağ/ } \\
\text { Sol }\end{array}$ & $\begin{array}{c}\text { Kırık } \\
\text { şekillenen } \\
\text { kemik } \\
\end{array}$ & $\begin{array}{c}\text { Kırığın dış } \\
\text { ortamla ilişkisi ve } \\
\text { Kırık çizgisi }\end{array}$ & Kırık sebebi \\
\hline 1 & 80 & Simental & $\mathrm{E}$ & 1 & Sol & Tibia & Kapalı Oblik & Doğuma yardım \\
\hline 2 & 86 & Simental & $E$ & 4 & Sol & Tibia & Kapalı Oblik & Doğuma yardım \\
\hline 3 & 93 & Montofon M. & $D$ & 2 & Sağ & Tibia & Kapalı Parçalı & Travma \\
\hline 4 & 95 & Montofon & D & 4 & Sol & Metakarpus & Kapalı Oblik & Travma \\
\hline 5 & 106 & Montofon & $E$ & 3 & Sol & Metatarsus & Kapalı Oblik & Doğuma yardım \\
\hline 6 & 133 & Montofon & $E$ & 10 & Sol & Metatarsus & Kapalı Transversal & Travma \\
\hline 7 & 163 & Simental & $E$ & 1 & Sol & Humerus & Açık Spiral & Doğuma yardım \\
\hline 8 & 164 & Simental M. & $D$ & 3 & Sağ/Sol & Mandibula & Açık Oblik & Doğuma yardım \\
\hline 9 & 165 & Simental & D & 30 & Sol & Metakarpus & Açık Transversal & Doğuma yardım \\
\hline 10 & 170 & Jersey & $E$ & 3 & Sağ & Femur & Kapalı Transversal & Travma \\
\hline 11 & 171 & Simental & $E$ & 3 & Sağ & Metakarpus & Kapalı Oblik & Doğuma yardım \\
\hline 12 & 172 & Simental & $D$ & 2 & Sağ/Sol & Mandibula & Açık Oblik & Doğuma yardım \\
\hline 13 & 178 & Simental & $E$ & 22 & Sağ & Humerus & Açık Oblik & Travma \\
\hline 14 & 196 & Simental & $E$ & 3 & Sağ & Metakarpus & Kapalı Transversal & Doğuma yardım \\
\hline 15 & 200 & Simental & $D$ & 4 & Sağ & Metatarsus & Kapalı Oblik & Travma \\
\hline 16 & 206 & Simental & D & 1 & Sol & Metakarpus & Kapalı Transversal & Doğuma yardım \\
\hline 17 & 217 & Simental & $E$ & 1 & Sol & Metatarsus & Açık Parçalı & Travma \\
\hline 18 & 222 & Montofon M. & $E$ & 4 & Sağ & Tibia & Açık Transversal & Travma \\
\hline 19 & 226 & Montofon & $E$ & 10 & Sağ & Metatarsus & Açık Transversal & Travma \\
\hline 20 & 232 & Simental & $E$ & 15 & Sol & Metakarpus & Açık Transversal & Doğuma yardım \\
\hline 21 & 241 & Montofon & $E$ & 6 & Sağ & Femur & Kapalı Parçalı & Doğuma yardım \\
\hline 22 & 249 & Montofon M. & $D$ & 3 & Sol & Femur & Kapalı Transversal & Travma \\
\hline 23 & 272 & Montofon & $E$ & 1 & Sağ/Sol & Metakarpus & Kapalı Transversal & Doğuma yardım \\
\hline 24 & 280 & Montofon & $E$ & 1 & Sağ & Metakarpus & Kapalı Oblik & Doğuma yardım \\
\hline 25 & 292 & Simental & $E$ & 5 & Sol & Skapula & Kapalı Oblik & Travma \\
\hline 26 & 294 & Simental & $D$ & 25 & Sağ & Tibia & Açık Oblik & Doğuma yardım \\
\hline 27 & 304 & Montofon M. & $E$ & 1 & Sağ/Sol & Mandibula & Açık Oblik & Doğuma yardım \\
\hline 28 & 312 & Simental & D & 1 & Sol & Metakarpus & Kapalı Transversal & Travma \\
\hline
\end{tabular}


Kırık olgularının oluşum sebeplerine bakıldığında; 16 buzağıda (\%57.14) doğum sırasında doğuma yardım etmek amacı ile yapılan bilinçsiz uygulamalar, 12 olguda (\%42.86) ise doğum sonrası travma sonucu olduğu belirlendi. Kırık olgularının $12^{\prime}$ si ön ekstremitede (\%42.86), 13'ü arka ekstremitede (\%46.43) ve 3 'ü ise mandibulada (\%10.71) görüldü.

Tespit edilen kırık olguları içerisinde en çok metakarpus kırıklarına ( $n=9, \% 32.14)$ rastlandı; bunu metatarsus ( $n=5, \% 17.86)$, tibia $(n=5, \% 17.86)$, femur $(n=3, \% 10.71)$, mandibula $(n=3, \% 10.71)$, humerus $(n=2, \% 7.14)$ ve skapula $(n=1, \% 3.57)$ kırıkları izledi. Kırık olgularının 3'ü bilateral mandibula (Şekil 1a), 1'i bilateral metakarpus kırığı iken 24'ü unilateraldi.

Kırık olgularının lokalizasyonu ve uygulanan sağaltım yöntemleri Tablo 2'de gösterilmiştir. Şekillenen kırık olguları; lokalizasyonuna göre 18 olguda diyafiz kırığı (\%64.29), 3 olguda (\%10.71) metafiz kırığı, 3 olguda korpus mandibula kırığı (\%10.71), 2 olguda epifiz kırığı (\%7.14), 1 olguda subtrochanter (\%3.57) ve 1 olguda ise supraglenoidal (\%3.57) kırık olarak saptandı (Tablo 2). Kırık olguları kırık çizgisinin seyrine göre incelendiğinde 13 olguda oblik (\%46.43) (Şekil 2a), 11 olguda transversal (\%39.29), 3 olguda parçalanmış (\%10.71) ve 1 olguda (\%3.57) ise spiral kırık olarak tespit edildi.

Tablo 2. Kırık olgularının lokalizasyonu ve kırık olgularına uygulanan sağaltım yöntemleri.

\begin{tabular}{|c|c|c|c|c|}
\hline No & Hasta kayıt protokol no & Kırık şekillenen kemik & Kırık lokalizasyonu & Uygulanan tedavi \\
\hline 1 & 80 & Tibia & Diyafiz & PVC destekli alçılı bandaj \\
\hline 2 & 86 & Tibia & Diyafiz & İntramedüller pin \\
\hline 3 & 93 & Tibia & Metafiz & İntramedüller pin \\
\hline 4 & 95 & Metakarpus & Diyafiz & PVC destekli alçılı bandaj \\
\hline 5 & 106 & Metatarsus & Diyafiz & İntramedüller pin \\
\hline 6 & 133 & Metatarsus & Diyafiz & PVC destekli alçılı bandaj \\
\hline 7 & 163 & Humerus & Diyafiz & İntramedüller pin, Serklaj \\
\hline 8 & 164 & Mandibula & Corpus & Akrilik eksternal fiksasyon \\
\hline 9 & 165 & Metakarpus & Diyafiz & PVC destekli bandaj \\
\hline 10 & 170 & Femur & Diyafiz & İntramedüller pin \\
\hline 11 & 171 & Metakarpus & Diyafiz & PVC destekli alçılı bandaj \\
\hline 12 & 172 & Mandibula & Corpus & Akrilik eksternal fiksasyon \\
\hline 13 & 178 & Humerus & Diyafiz & İntramedüller pin \\
\hline 14 & 196 & Metakarpus & Metafiz & PVC destekli alçılı bandaj \\
\hline 15 & 200 & Metatarsus & Diyafiz & PVC destekli alçılı bandaj \\
\hline 16 & 206 & Metakarpus & Epifiz & PVC destekli alçılı bandaj \\
\hline 17 & 217 & Metatarsus & Diyafiz & İntramedüller pin, Serklaj \\
\hline 18 & 222 & Tibia & Diyafiz & PVC destekli bandaj \\
\hline 19 & 226 & Metatarsus & Diyafiz & PVC destekli bandaj \\
\hline 20 & 232 & Metakarpus & Diyafiz & PVC destekli bandaj \\
\hline 21 & 241 & Femur & Subtrochanter & İntramedüller pin, Serklaj \\
\hline 22 & 249 & Femur & Metafiz & İntramedüller pin \\
\hline 23 & 272 & Metakarpus & Epifiz & PVC destekli alçılı bandaj \\
\hline 24 & 280 & Metakarpus & Diyafiz & PVC destekli alçılı bandaj \\
\hline 25 & 292 & Skapula & Supraglenoidal & Serklaj \\
\hline 26 & 294 & Tibia & Diyafiz & PVC destekli bandaj \\
\hline 27 & 304 & Mandibula & Corpus & Akrilik eksternal fiksasyon \\
\hline 28 & 312 & Metakarpus & Diyafiz & PVC destekli alçılı bandaj \\
\hline
\end{tabular}

Sağaltımda konservatif yöntem olarak toplam 10 olguya PVC destekli alçılı bandaj (Şekil 2b), 5 olguya PVC destekli bandaj, operatif olarak 6 olguya intramedüller pin, 3 olguya intramedüller pin ve serklaj, 3 olguya akrilik eksternal fiksasyon (Şekil 1b) ve 1 olguya serklaj teli uygulandı. PVC destekli alçılı bandaj ile kapalı redüksiyonu gerçekleştirilen 10 olgu metakarpus $(n=7)$, metatarsus $(n=2)$ ve tibia $(n=1)$; PVC destekli bandaj uygulanan 5 olgu ise metakarpus $(n=2)$, metatarsus $(n=1)$ ve tibia $(n=2)$ kırığı olarak belirlendi (Tablo 2). Elde edilen radyolojik muayene bulgularına göre PVC destekli alçılı bandaj uygulanan olguların 9' unda iyileşme
(Şekil 2c) sağlandı. Bilateral kapalı metakarpal kırık şekillenen sadece 1 olguda (Olgu no=23) hasta sahibinin kötü bakım ve idaresi sonucu 1 ay sonraki kontrolde açık kırık şekillendiği, kırık bölgesinin PVC atel destekli alçılı bandaja rağmen dışkı ile bulaşık olduğu ve yapılan tüm tedavilere rağmen ölüm şekillendiği belirlendi.

Operatif kırık sağaltımı uygulanan 13 olgudan 10'unda tam bir iyileşme görülürken (Şekil 1c), intramedüller pin uygulanan parçalı kapalı tibia kırığına sahip 1 olguda (Olgu no=3) ve spiral açık humerus kırığına sahip 1 olguda (Olgu no=7) postoperatif 1 . günde nedeni bilinmeyen ölüm 
gözlendi. Doğumdan 15 gün sonra travmaya bağlı olarak kırık şekillenen ve şekillendikten 7 gün sonra hasta sahibi tarafından ampirik yöntemlerle bandaja alınmış olarak kliniğe getirilen oblik açık humerus kırığına sahip 1 olgunun (Olgu no=13) ise postoperatif 15. günde yara hattındaki enfeksiyona bağlı olarak öldüğü hayvan sahibinden öğrenildi.

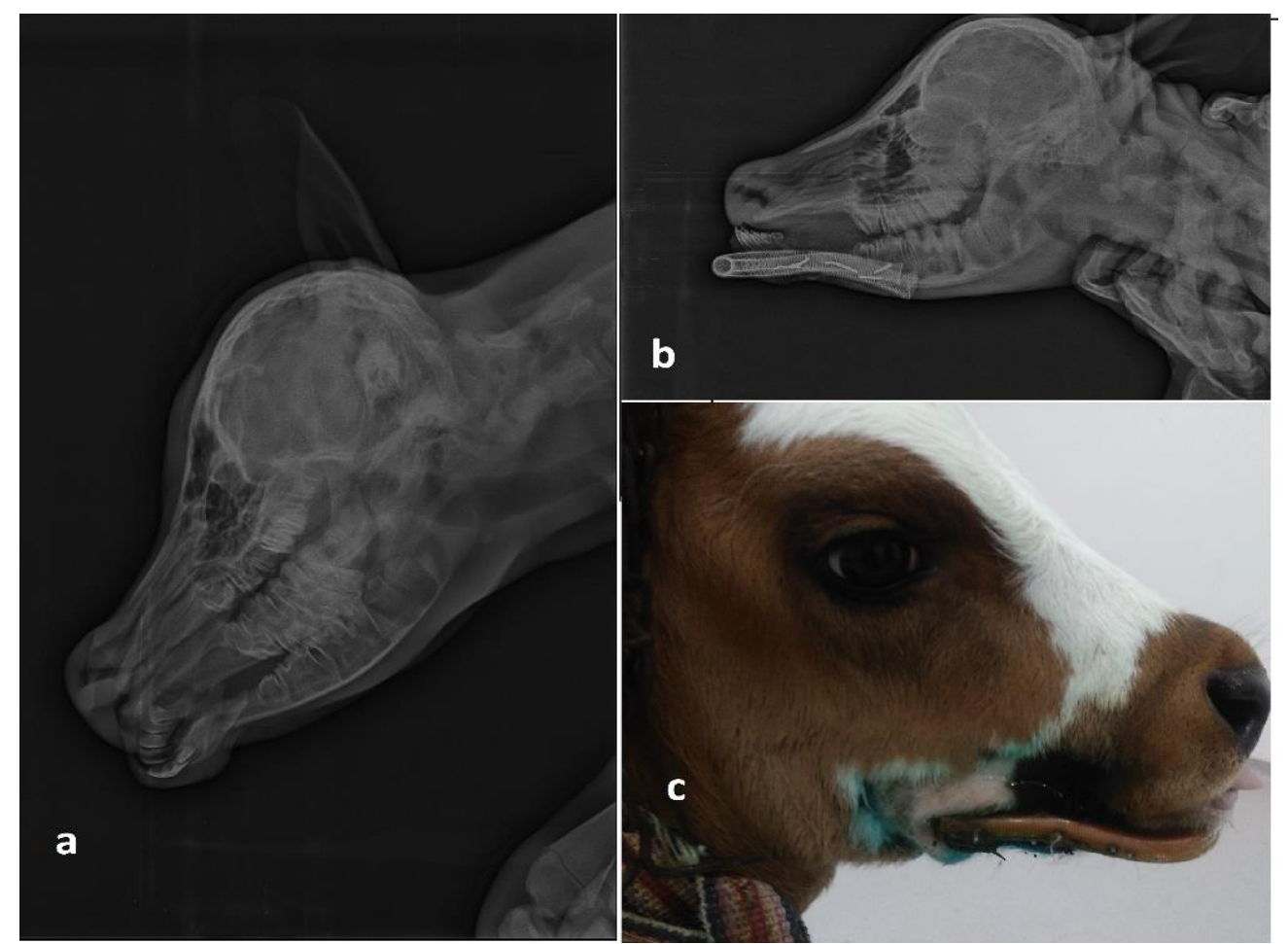

Şekil 1. Bir olguda bilateral mandibula kırığı (a) ve akrilik eksternal fiksasyon ile tedavisi (b). Postoperatif 30. gün görünümü (c) (Olgu no=12).

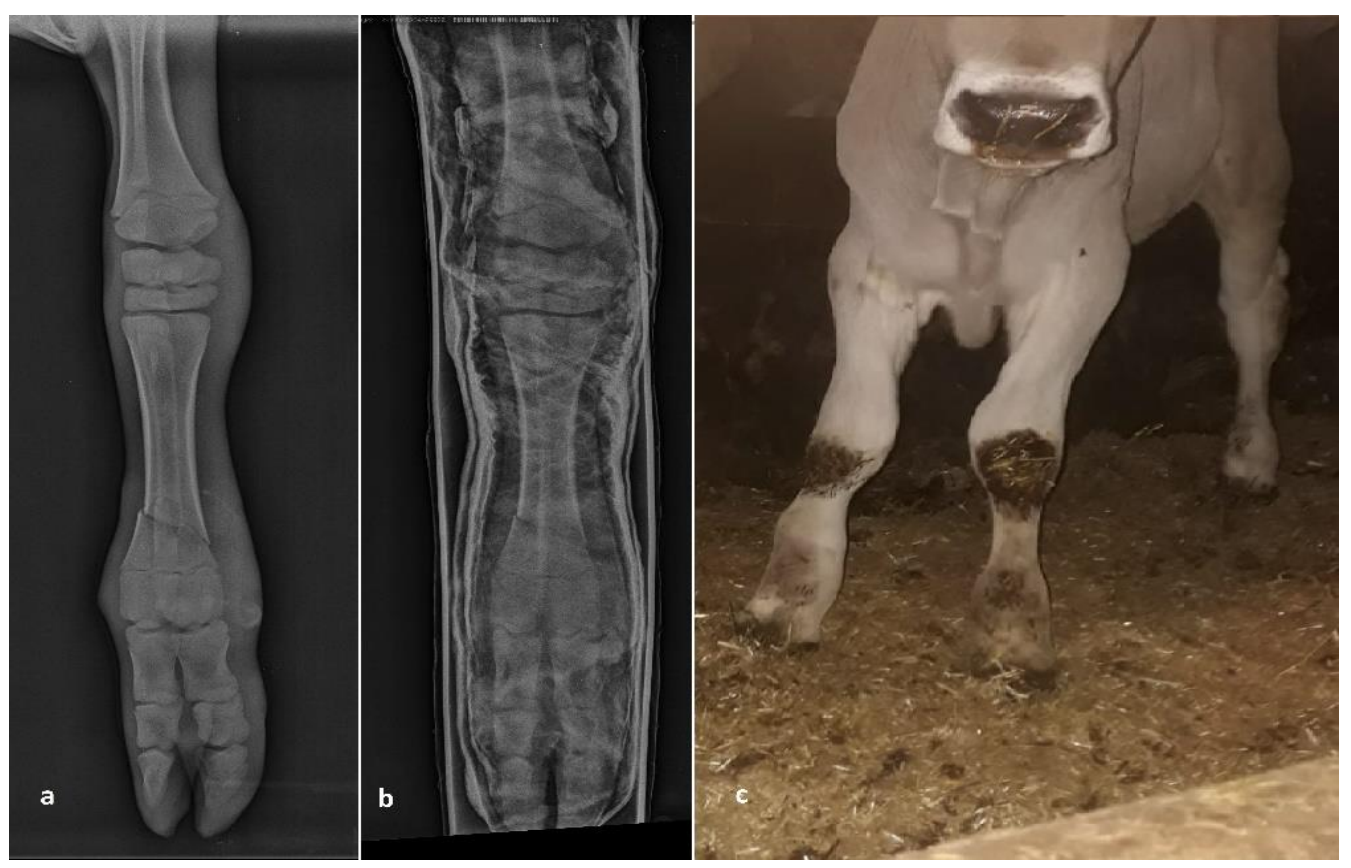

Şekil 2. Bir olguda oblik diyafizer metakarpal kırı̆̆ı (a) ve PVC destekli alçılı bandaj ile tedavisi (b). Postoperatif 60. gün görünümü (c) (Olgu no=24). 


\section{Tartışma ve Sonuç}

Yeni doğan buzağılarda kırık olguları çoğunlukla suni tohumlama ile ilk kez gebe kalan ineğin yaşı, besi durumu, pelvik kanalının dar olması, doğacak olan buzağının büyüklüğü ve erkek olması, doğacak olan buzağının uterustaki doğum pozisyonu gibi sebeplere bağlı olan güç doğum esnasında şekillenmektedir (Kalkan ve ark., 1993; Kırşan ve ark., 1999). Kırık oluşumundaki en önemli nedenlerden biri de güç doğum esnasında hayvan sahiplerinin yaptıkları bilinçsiz müdahalelerdir.

Doğacak olan yavrunun erkek olması bir güç doğum riskidir (Kalkan ve ark., 1993). Güç doğum esnasında şekillenen kırık olgularına erkek buzağılar dişilere oranla daha yatkındır (Aksoy ve ark., 2009). Bu çalışmada da; kırık olgularının erkek buzağılarda (\%64.29) dişi buzağılara (\%35.71) oranla daha fazla görülmesi; güç doğuma bağlı şekillenen ekstremite kırıklarının oluşmasında cinsiyetin etkili olduğunu destekler niteliktedir. Irklara göre bakıldığında ise kırık olgularının en fazla Simental ırkı buzağılarda (\%53.57) görülmesi; bu buzağıların vücut yapısının çalışmadaki diğer ırk buzağıların vücut yapısından daha iri olması ile açıklanabilir.

Yeni doğan buzağılarda gözlenen kırık olgularının büyük çoğunluğunu doğum sırasında, özellikle güç doğum olgularında doğuma yardım amacıyla uygulanan aşırı çekme işlemi veya yanlış müdahaleler sonucu şekillenen kırıklar oluşturmaktadır (Arıcan ve ark., 2014; Ferguson, 1994; Kostlin ve ark., 1990; Öztaş ve Avki, 2015). Bu çalışmada kırık olgularının 16'sının (\%57.14) doğum esnasında, 12'sinin (\%42.86) ise doğumdan sonra çeşitli travmatik sebeplere bağlı olarak oluştuğunun belirlenmesi literatür (Arıcan ve ark., 2014; Ferguson, 1994; Kostlin ve ark., 1990) bilgiyi desteklemektedir.

Buzağılarda karşılaşılan kırıklar en fazla metakarpus ve metatarsus (\%50), femur (\%14), tibia (\%12), radius-ulna (\%7), ve humerus (\%5) kırıklarıdır (Görgül ve ark. 2004). Arıcan ve ark. (2014) kırık olgularının \%60.6'sının; Görgül ve ark. (2004) olguların \%67.7'sinin; Kostlin ve ark. (1990) \%26.3'ünün metakarpusta rastlandığını bildirmişlerdir. Çalışmada kırık olgularının \%32.14 oranla en çok metakarpusta şekillendiğinin görülmesi ilgili araştırmacıların verileri ile uyumlu olduğunu göstermektedir.

Uzun ekstremitelerde şekillenen kırık olgularının daha çok diyafiz bölgesinde tespit edildiği belirtilmektedir (Fubini ve Ducharme, 2004). Yapılan bu çalışmada da; \%64.29 oranında diyafiz kırığı saptanması bu bilgiyi desteklemektedir.

Buzağılarda şekillenen kırık olgularının sağaltımı konservatif ve operatif olmak üzere iki şekilde yapılmaktadır (Belge ve ark., 2016).
Konservatif sağaltımda en sık kullanılan yöntem bandaj uygulamasıdır. Bunlar atelli (PVC, alüminyum, tahta), alçılı ve termoplastik bandajlardır (Arıcan ve ark., 2014; Görgül ve ark., 2004; Martens ve ark., 1998). Kırıkların operatif sağaltımında ise internal (intramedüller pin, serklaj, vida, plak, interlocking pin) ve eksternal fiksasyon yöntemlerinden faydalanılır (Arıcan ve ark., 2014; Belge ve ark., 2016; Durmuş ve ark., 2009; Salcı ve ark., 2016; St-Jean ve Debowes, 1991). Konservatif sağaltım amacıyla 10 olguya PVC destekli alçılı bandaj ve 5 olguya PVC destekli bandaj uygulandı. Konservatif sağaltım uygulanan toplam 15 olgudan 1'inde (Olgu no=23) ölüm şekillendi. Operatif olarak 6 olguya intramedüller pin, 3 olguya intramedüller pin ve serklaj, 3 olguya akrilik eksternal fiksasyon ve 1 olguya serklaj teli uygulandı. Operatif sağaltım uygulanan 13 olgunun 3'ünde (Olgu no=3, 7, 13) ölüm şekillendi.

Yapılan bu çalışmada; buzağılarda şekillenen kırık olgularının büyük çoğunluğunu (\%57.14) güç doğum olgularına veteriner hekim yerine hayvan sahiplerinin kendileri tarafından uygulanan yanlış müdahaleler sonucu şekillenen kırıklar oluşturdu. Travmaya bağlı şekillenen kırık olgularının (\%42.86) ise yine hayvan sahiplerinin yeni doğmuş buzağılar için gerekli önlemleri almamaları neticesinde şekillendiği anlaşılmıştır.

Sonuç olarak hayvan sahiplerinin güç doğum olgularına müdahalede bulunmamaları, buzağıların doğumdan sonra travmalara maruz kalmamaları için belli bir döneme kadar gereken önlemleri almaları, buzağılarda şekillenen kırık olgularına ampirik yöntemlerle müdahale etmemeleri ve en kısa sürede bir veteriner hekime başvurmaları konusunda bilinçlendirilmeleri gerektiği kanısına varıldı.

\section{Kaynaklar}

Aksoy Ö, Özaydın I, Kılıç E, Savaş Ö, Güngör E, Başak K, Hasan O, 2009: Evaluation of fractures in calves due to forced extraction during dystocia: 27 cases (20032008). Kafkas Üniv Vet Fak Derg, 15, 339-344.

Arıcan M, Erol H, Esin E, Parlak K, 2014: A retrospective study of fractures in neonatal calves: 181 cases (2002-2012). Pak Vet J, 34, 247-250.

Belge A, Akın I, Gülaydın A, Yazıcı MF, 2016: The treatment of distal metacarpus fracture with locking compression plate in calves. Turk J Vet Anim Sci, 40, 234-242.

Durmuş AS, Karabulut E, Sağlıyan A, 2009: Yenidoğan bir buzağıda suprakondiler femur kırığı olgusu ve operatif sağaltımı. FÜ Sağ Bil Vet Derg, 23, 119-122.

El-Shafaey EA, Aoki T, Ishii M, Yamada K, 2014: Conservative management with external coaptation technique for treatment of a severely comminuted fracture of the proximal phalanx in a Holstein- 
Friesian cow. Iranian Journal of Veterinary Research, 15, 300-303.

Ferguson JG, 1994: Femoral fractures in the new born calf, biomechanics and ethiological considerations of practitioners. Can Vet J, 35, 626-630.

Ferguson JG, Dehghani S, Petrali EH, 1990: Fractures of the femur in new born calves. Can Vet J, 31, 289291.

Fubini S, Ducharme NG, 2004: Farm animal surgery. St. Louis, pp. 288-323.

Gangl M, Grulke S, Serteyn D, Touati K, 2006: Retrospective study of 99 cases of bone fractures in cattle treated by external coaptation or confinement. Veterinary Record, 158, 264-268.

Görgül, OS, Seyrek-Intaş D, Çelimli N, Çeçen G, Salcı H, Akın i, 2004: Buzağılarda kırık olgularının değerlendirilmesi: 31 olgu (1996-2003). Veteriner Cerrahi Dergisi, 10, 16-20.

Kalkan C, Deveci H, Apaydın AM, Öcal H, Timurkan H, Çetin H. Kaygusuzoğlu E, 1993: Elazığ ve çevresinde 1985-1992 yılları arasında ineklerde görülen güç doğumların sebepleri, tedavisi ve alınan sonuçlar üzerine çalışma. SÜ Vet Derg, 9, 53-56.

Kırşan I, Şenünver A, Çolak A, Gürbulak K, 1999: Sığırlarda güç doğuma müdahalenin Denaverinhydrochlorid ile kolaylaştırılması. Kafkas Üniv Vet Fak Derg, 5, 47-53.

Kostlin RG, Nuss K, Elma E, 1990: Metacarpal and metatarsal fractures in cattle. Treatment and results. Tierarztl Praxis, 18, 131-144.
Martens A, Steenhaut, M Gasthuys, F, De Cupere C, De Moor A, Verschooten F, 1998: Conservative and surgical treatment of tibial fractures in cattle. Vet Rec, 143, 12-16.

Nuss K, Spiess A, Feist M, Köstlin R, 2011: Treatment of long bone fractures in 125 newborn calves: A retrospective study. Tieraerztl Prax, 39, 15-26.

Öztaş E, Avki S, 2015: Evaluation of acrylic pin external fixation (APEF) system in metacarpal fractures of newborn calves: cheap but effective? Kafkas Üniv Vet Fak Derg, 21, 433-436.

Salcı H, Canatan U, Çetin M, 2016: Bir buzağıda SalterHarris Tip I metacarpus kırığının açılı kama plağı ile sağaltımı. Uludag Univ J Fac Vet Med, 35, 57-60.

St-Jean G, DeBowes RM, 1992: Transfixation pinning and casting of radial-ulnar fractures in calves: A review of three cases. Can Vet J, 33, 257-262.

St-Jean G, Debowes RM, 1991: Transfixation pinning and casting of tibial fractures in calves: Five cases (19851989). J Am Vet Med Assoc, 198, 139-143.

Tulleners EP, 1986: Metacarpal and metatarsal fractures in dairy cattle: 33 cases (1979-1985). J Am Vet Med Assoc, 189, 463-468.

*Yazışma adresi: Ibrahim YURDAKUL

Sivas Cumhuriyet Üniversitesi Veteriner Fakültesi, Cerrahi Anabilim Dalı, Sivas, Türkiye.

E-mail: ibrahimyurdakul5858@hotmail.com 